\title{
Article
}

\section{Biomechanical predictors of ball velocity during punt kicking in elite rugby league kickers}

Sinclair, Jonathan Kenneth, Taylor, Paul John, Atkins, Stephen and Hobbs, Sarah Jane

Available at http://clok.uclan.ac.uk/16797/

Sinclair, Jonathan Kenneth ORCID: 0000-0002-2231-3732, Taylor, Paul John ORCID: 0000-0002-9999-8397, Atkins, Stephen and Hobbs, Sarah Jane ORCID: 0000-0002-1552-8647 (2016) Biomechanical predictors of ball velocity during punt kicking in elite rugby league kickers. International Journal of Sports Science \& Coaching, 11 (3). pp. 356-364. ISSN 1747-9541

It is advisable to refer to the publisher's version if you intend to cite from the work. http://dx.doi.org/10.1177/1747954116644062

For more information about UCLan's research in this area go to http://www.uclan.ac.uk/researchgroups/ and search for <name of research Group>.

For information about Research generally at UCLan please go to http://www.uclan.ac.uk/research/

All outputs in CLoK are protected by Intellectual Property Rights law, including Copyright law. Copyright, IPR and Moral Rights for the works on this site are retained by the individual authors and/or other copyright owners. Terms and conditions for use of this material are defined in the policies page. 
1 Biomechanical predictors of ball velocity during punt kicking in elite rugby league

\section{Contact Details:}

9 Jonathan Sinclair,

10 School of Sport Tourism and Outdoors,

11 University of Central Lancashire,

12 Preston,

13 PR1 2HE.

e-mail: jksinclair@uclan.ac.uk

\section{Word count:}

Main text (3662):

Main text (including references): (4578);

\section{INTRODUCTION}

\section{kickers}

\section{${ }^{1}$ Sinclair J, ${ }^{2}$ Taylor P.J, ${ }^{1}$ Atkins S, and ${ }^{1}$ Hobbs S.J}

1. Centre for Applied Sport and Exercise Sciences, University of Central Lancashire

2. School of Psychology, University of Central Lancashire

Keywords: rugby, kicking, kinematics, ball velocity.

\begin{abstract}
Punt kicking is integral to the attacking and defensive elements of rugby league and the ability to kick the ball with high velocity is desirable. This study aimed to identify important technical aspects of kicking linked to the generation of ball velocity. Maximal punt kicks were obtained from six elite rugby league kickers using a ten camera motion capture system. Three-dimensional kinematics of the lower extremities were obtained. Regression analysis with ball velocity as criterion was used to identify the kinematic parameters associated with the development of ball velocity. The regression model yielded an adj $\mathrm{R}^{2}=0.76$, $\mathrm{p} \leq 0.01$. Two parameters were identified: knee extension angular velocity of the kicking limb at impact $\left(\mathrm{R}^{2}=0.50\right)$ and peak flexion angular velocity of the kicking hip $\left(\mathrm{R}^{2}=0.26, \mathrm{p} \leq 0.01\right)$. It is conceivable that players may benefit from exposure to coaching and strength techniques geared towards the modification of kicking mechanics specific to this study.
\end{abstract}


Rugby league is an extremely popular sporting discipline in a number of countries, particularly England, Australia and New Zealand. Kicking has become increasingly important in rugby league. Punt kicking is integral to rugby league and a desired element of any player's skill set is the ability to kick the rugby ball long distances. Lim et al., [1] proposed following their examination of game actions contributing to performance that effective kicking is of greater importance than any of the set piece elements of rugby.

In professional rugby league effective punt kicking is important for attacking play, typically in the form of a 40-20 where a player behind his side's 40 metre line kicks the ball over the side-lines of the field of play past the opponent's 20 metre line. A successful 40-20 typically gives the offensive side attacking possession by moving the team from their own 40 metre line to the position where the ball went out inside the opposing team's 20 metre area. Furthermore, punt kicking for maximal distance is also important for defensive play near the end of the tackle count, whereby the ball will often find its way to the best kicker on the team who will return possession of the ball to the other side in the most favourable position for his team by kicking as far down the opposite end of the field as possible. Thus ensuring the opposing team have to commence their attack in position as far from the defensive try line as possible.

It is well known that a greater projection velocity results in a greater kick distance [2]. Maximal punt kicking, with the aim of achieving high resultant ball velocity, occurs many times during sport [3]. Punt kicking for maximum distance in rugby league has received a paucity of research attention. However a select number of studies of punt kicking biomechanics have been carried out in other sports [4-7]. The punt kick is described as a proximal-distal sequence of movements including a run up, planting of the stance/support limb, and ball strike with the kicking limb [8]. During maximal velocity kicking, the support limb serves as the axis of rotation for the swinging leg. The generation of power begins at the hip joint, and as the kicking limb comes around, a sequential transfer of momentum from the hip to the ankle joint causes an increase in foot speed [7]. Ball, [4] conducted the only study to investigate mechanics of the punt kick in relation to the generation of ball velocity in Australian Rules football. Ball, [4] showed that the most influential parameter was the velocity of the foot at ball contact. However other key parameters linked to the development of ball velocity were shank angular velocity at ball contact, the linear distance of the last stride before ball contact and the position of the ball relative to the body.

Therefore whilst the importance of maximal distance punt kicking in professional rugby league has been well documented and punt kicking mechanics have received considerable attention in other sports, there has been no examination of the technical elements pertinent to the development of kicking distance using elite rugby league players. This study therefore aims to identify important technical aspects of distance kicking linked to the generation of high ball velocity using regression analyses.

82

\section{METHODS}

84 Participants 
Six elite standard male rugby league kickers volunteered to take part in this investigation (age $24.75 \pm 4.11$ years; height $178.25 \pm 5.68 \mathrm{~cm}$; body mass $82.75 \pm$ $7.50 \mathrm{~kg}$ ). The participants were contracted to a professional rugby league club in England. Although not all of the players typically performed kicks during games all six players practiced punt kicking during training three times per week during the season. All were free from lower extremity pathology and provided written informed consent in accordance with the procedures outlined in the declaration of Helsinki. Ethical approval for this project was obtained from the School of Psychology ethics committee at the University of Central Lancashire.

\section{Procedure}

A ten camera motion analysis system (Qualisys ${ }^{\mathrm{TM}}$ Medical AB, Goteburg, Sweden) captured kinematic data at $250 \mathrm{~Hz}$ from each participant performing maximal punt kicks with a $5 \mathrm{~m}$ run up. A standard sized rugby ball was kicked from the centre of the laboratory into a net positioned $8 \mathrm{~m}$ away. Dynamic calibration of the motion analysis system was performed before each data collection session.

The anatomical marker configuration utilized for this study was based on the calibrated anatomical systems technique (CAST) method [9] allowing the thorax, pelvis and bilateral foot, shank and thigh segments to be defined and tracked. Retro-reflective markers (19 mm diameter) were attached in the following locations; bilaterally to the $1^{\text {st }}$ and $5^{\text {th }}$ metatarsal heads, calcaneus, medial and lateral malleoli, medial and lateral epicondyle of the femur, greater trochanter, right and left posterior super iliac spine (PSIS) and right and left anterior super iliac spine (ASIS). Technical tracking clusters were positioned on the right and left thigh and right and left shank. The hip joint centre was determined using regression equations via the positions of the PSIS and ASIS markers [10]. The tracking clusters were comprised of four $19 \mathrm{~mm}$ spherical reflective markers mounted to a thin sheath of lightweight carbon fiber with a length to width ratios of 1.5:1 and 2.05:1, in accordance with the previously established guidelines [11]. A static trial was captured to define the pelvis, thighs, feet and tibial segments of both the left and right limbs, following which markers not used for tracking the segments during motion, were removed prior to the collection of dynamic information. The rugby ball was treated as a segment using the motion capture system allowing the centre of the ball to be located. This involved placing two markers at either end of the ball to obtain the proximal and distal aspects, and a further tracking marker was positioned in the middle. Following the static trial markers at the end of the ball that was to be kicked were removed. The motion camera system therefore tracked the rugby ball using three reflective markers, allowing ball release speed to be quantified. Twenty trials were recorded from each player.

\section{Data Processing}

Kinematic parameters were quantified using Visual 3-D (C-Motion Inc, Germantown, USA) and filtered at $15 \mathrm{~Hz}$ using a zero-lag low pass Butterworth $4^{\text {th }}$ order filter. This was selected as being the frequency at which $95 \%$ of the signal power was maintained, following a fast fourier transform (FFT). Five trials of maximal punt kicking were averaged for each participant. Stance limb kinematics were defined by the instances of footstrike and take-off from force platform data, whilst kicking limb kinematics were defined from stance limb touch down to ball contact. Stance was defined as the time 
over which $20 \mathrm{~N}$ or greater of vertical force was applied to the force platform [12].

134 Using the protocol documented by Sinclair et al., [13], ball contact was determined

135 using the change in velocity of the ball. Ball contact was identified as the instance at

136 which the vertical velocity of the ball changed from negative to positive. The trials were

137 split following ball contact in order to quantify ball velocity (Sinclair et al., 2014). This

138 served to reduce the potential for distortion of the markers positioned onto the ball as a

139 result of the foot impact, allowing ball velocity to be more accurately quantified [14].

140 Angles were created about an XYZ cardan sequence referenced to co-ordinate systems

141 created about the proximal end of the segment, where $\mathrm{X}=$ sagittal plane rotations; $\mathrm{Y}=$

142 coronal plane rotations and $\mathrm{Z}=$ transverse plane rotations. Three-dimensional kinematic

143 measures from the hip, knee and ankle which were extracted for statistical analysis were

144 1) angle at footstrike, 2) angle at toe-off, 3) angle at ball impact, 4) range of motion

145 during stance, 5) peak angle during stance, 6) relative range of motion from footstrike to

146 peak angle, 7) angular velocity at footstrike, 8) angular velocity at toe-off, 9) angular

147 velocity at ball impact and 10) peak angular velocity.

\section{Statistical analyses}

Multiple regression analyses with ball velocity as criterion and the 3-D kinematic parameters as independent variables were carried out using a forward stepwise procedure with significance accepted at the $\mathrm{p} \leq 0.05$ level. The independent variables were examined for co-linearity prior to entry into the regression model using a Pearson's correlation coefficient matrix and those exhibiting high co-linearity $\mathrm{R} \geq 0.7$ were removed. All statistical procedures were conducted using SPSS 19.0 (SPSS Inc, Chicago, USA).

\section{RESULTS}

\section{Ball and foot velocities}

The results revealed mean \pm standard deviation ball velocities of $26.91 \pm 5.45 \mathrm{~m} . \mathrm{s}^{-1}$ and foot linear velocities of $20.16 \pm 3.84 \mathrm{~m} \cdot \mathrm{s}^{-1}$.

\section{Regression analyses}

166

167

168

Figures 1-4 and tables 1-2 present the mean \pm standard deviation 3-D kinematic parameters from both the stance and kicking limbs. The overall regression model yielded an $\mathrm{R}=0.95, \mathrm{R}^{2}=0.89$ and $\operatorname{Adj} \mathrm{R}^{2}=0.76, \mathrm{p} \leq 0.01$. Two biomechanical parameters were obtained as significant predictors of ball velocity. Knee extension angular velocity of the kicking limb in the sagittal plane $(B=0.90, \mathrm{t}=6.95)$ Adj $\mathrm{R}^{2}=0.50$, $\mathrm{p} \leq 0.01$ and peak angular velocity if the hip also in the sagittal plane $(B=0.29, \mathrm{t}=4.60)$ Adj $R^{2}=0.26, p \leq 0.01$ were found to be significant predictors of ball velocity. 


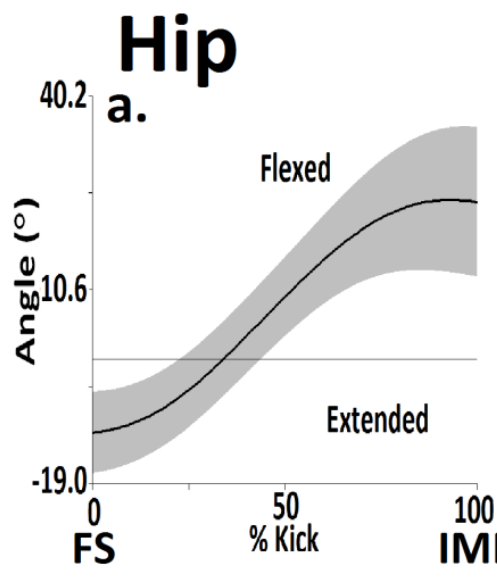

Knee

129.6

a.

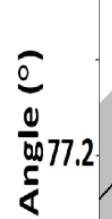

Flexed

$-12.5$

Ankle

a. Plantar-flexed
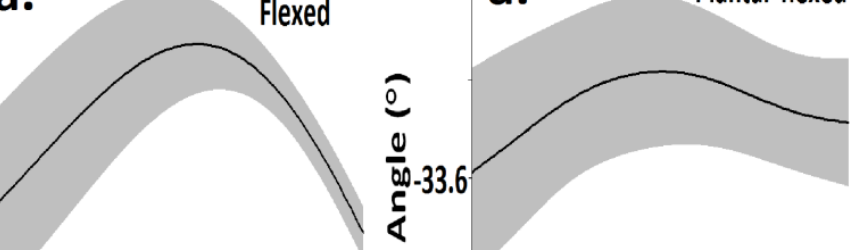

Extended

Dorsi-flexed
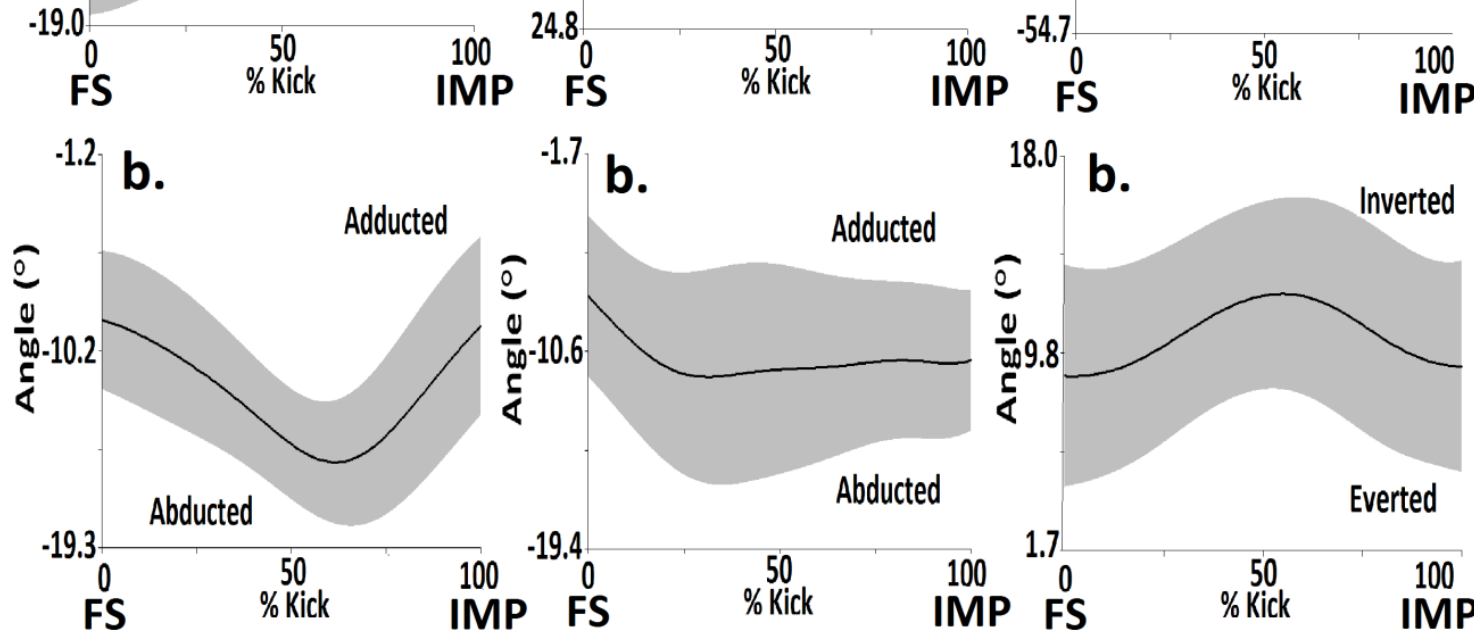

-1.7 b.

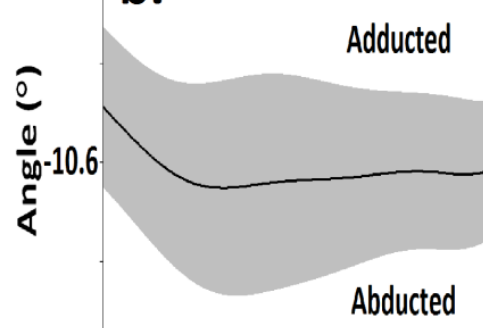

18.0
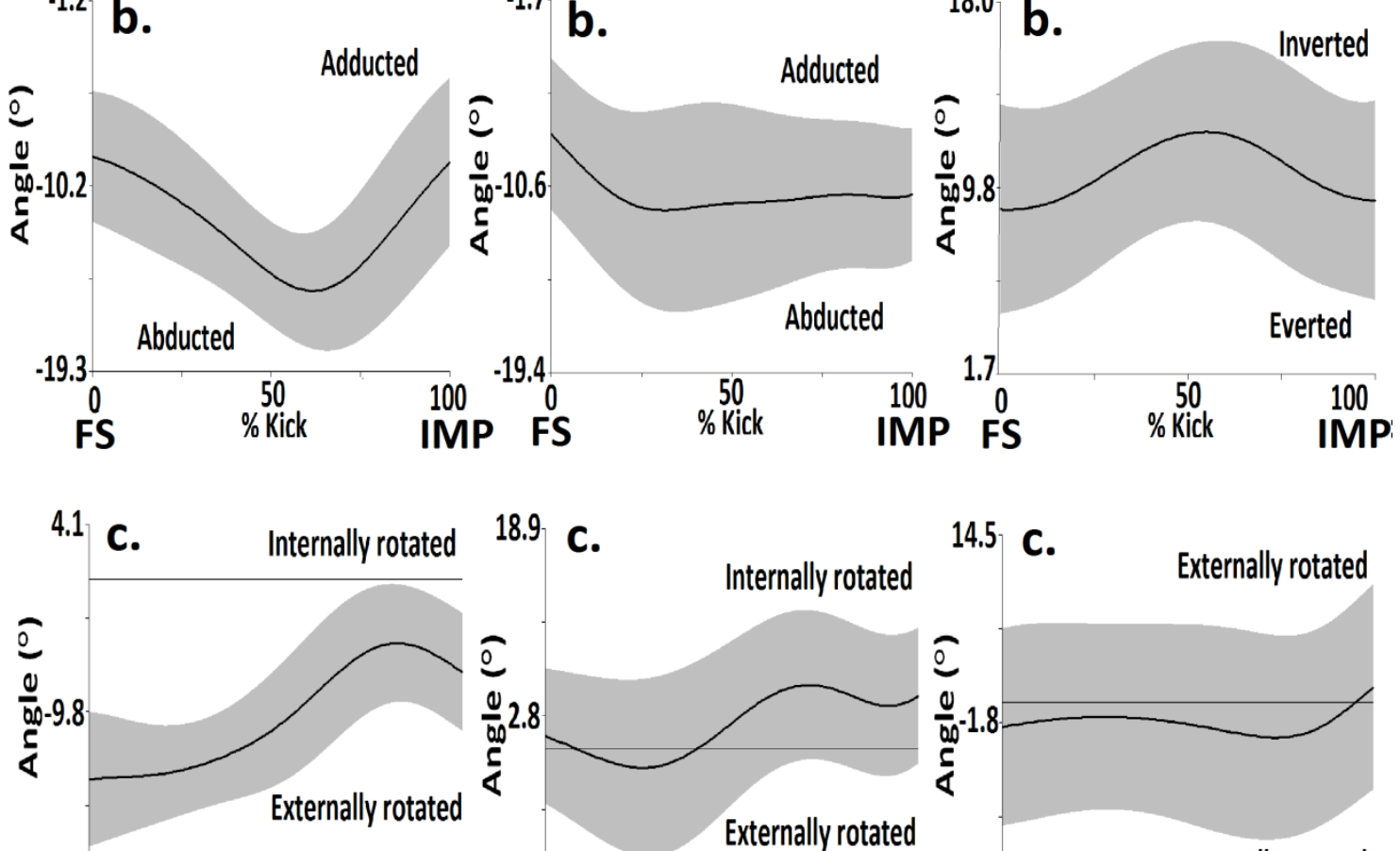

18.9 C.

IMP FS

IMP:
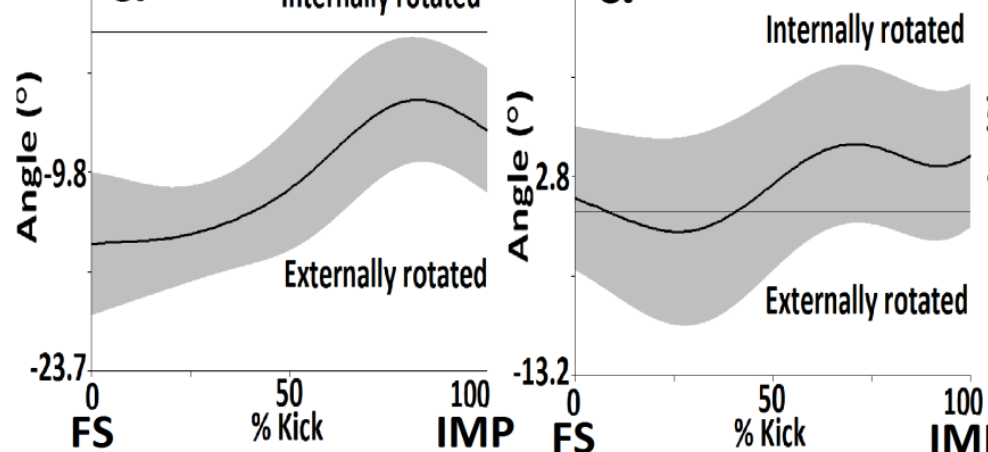

14.5 C.

C. Externally rotated $-13.2$

FS

\% Kick

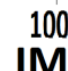

IMP FS

Internally rotated

Figure 1: Mean and standard deviation hip, knee and ankle joint angular kinematics

181 from the kicking limb in the a. sagittal, b. coronal and c. transverse planes (shaded area is $1 \pm \mathrm{SD})(\mathrm{FS}=$ stance limb footstrike, IMP = ball impact). 

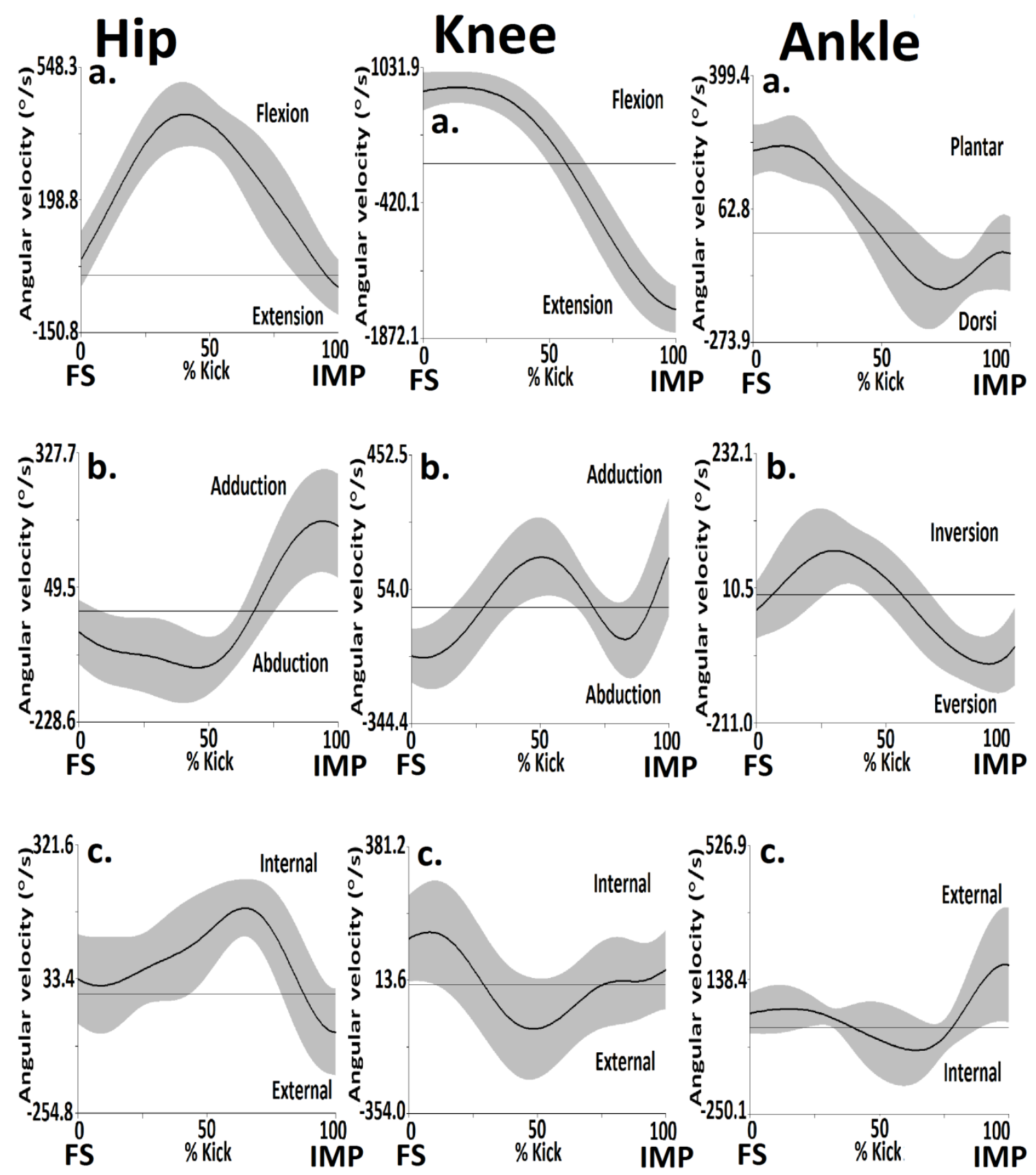

Figure 2: Mean and standard deviation hip, knee and ankle joint angular velocities from the kicking limb in the a. sagittal, b. coronal and c. transverse planes (shaded area is 1 $\pm \mathrm{SD})(\mathrm{FS}=$ stance limb footstrike, IMP = ball impact).. 
192 Table 1: Hip, knee and ankle joint angles (means and standard deviations) from both the stance and kicking limbs.

\begin{tabular}{|c|c|c|c|c|c|c|}
\hline & \multicolumn{2}{|c|}{ Hip } & \multicolumn{2}{|c|}{ Knee } & \multicolumn{2}{|c|}{ Ankle } \\
\hline Sagittal Plane (+ =flexion/ - =extension) & Kick & Stance & Kick & Stance & Kick & Stance \\
\hline Angle at Footstrike $\left(^{\circ}\right)$ & $-11.0 \pm 6.5$ & $49.2 \pm 10.5$ & $63.6 \pm 26.9$ & $26.7 \pm 3.6$ & $-34.3 \pm 12.3$ & $-71.0 \pm 10.7$ \\
\hline Angle at Toe-off / Ball impact $\left(^{\circ}\right)$ & $24.7 \pm 12.0$ & $-3.7 \pm 7.6$ & $62.7 \pm 4.1$ & $26.0 \pm 7.0$ & $-28.6 \pm 8.0$ & $-35.5 \pm 9.0$ \\
\hline Range of Motion $\left(^{\circ}\right)$ & $35.7 \pm 6.1$ & $53.0 \pm 13.7$ & $24.6 \pm 9.1$ & $0.7 \pm 5.3$ & $6.2 \pm 6.8$ & $35.5 \pm 11.9$ \\
\hline Peak Range of Motion $\left(^{\circ}\right)$ & $36.5 \pm 5.9$ & $58.2 \pm 14.6$ & $51.2 \pm 16.9$ & $16.6 \pm 4.9$ & $12.0 \pm 5.1$ & $3.9 \pm 2.8$ \\
\hline Peak Angle $\left(^{\circ}\right)$ & $25.5 \pm 11.7$ & $-9.0 \pm 9.7$ & $114.8 \pm 13.1$ & $43.3 \pm 6.7$ & $-22.3 \pm 9.2$ & $-74.1 \pm 8.6$ \\
\hline \multicolumn{7}{|l|}{$\begin{array}{c}\text { Coronal plane }(+=\text { adduction/ - } \\
=\text { abduction })\end{array}$} \\
\hline Angle at Footstrike $\left(^{\circ}\right)$ & $-8.8 \pm 3.0$ & $-8.3 \pm 7.9$ & $-7.7 \pm 3.8$ & $6.1 \pm 5.3$ & $9.1 \pm 4.4$ & $-5.2 \pm 4.5$ \\
\hline Angle at Toe-off / Ball impact $\left(^{\circ}\right)$ & $-9.2 \pm 4.0$ & $-14.1 \pm 6.1$ & $-10.5 \pm 3.7$ & $-6.9 \pm 5.5$ & $9.6 \pm 4.5$ & $-3.3 \pm 7.9$ \\
\hline Range of Motion $\left(^{\circ}\right)$ & $3.4 \pm 1.4$ & $9.2 \pm 4.6$ & $2.8 \pm 2.0$ & $13.0 \pm 0.8$ & $4.1 \pm 2.8$ & $4.2 \pm 4.4$ \\
\hline Peak Range of Motion $\left(^{\circ}\right)$ & $6.9 \pm 3.6$ & $8.0 \pm 5.1$ & $6.0 \pm 3.2$ & $13.1 \pm 8.4$ & $4.3 \pm 2.8$ & $6.8 \pm 5.0$ \\
\hline Peak Angle $\left({ }^{\circ}\right)$ & $-15.7 \pm 2.5$ & $-15.5 \pm 3.9$ & $-13.7 \pm 4.1$ & $-7.0 \pm 3.3$ & $13.4 \pm 3.5$ & $-0.8 \pm 9.0$ \\
\hline \multicolumn{7}{|l|}{$\begin{array}{c}\text { Transverse plane }(+=\text { internal/ - } \\
=\text { external })\end{array}$} \\
\hline Angle at Footstrike $\left(^{\circ}\right)$ & $-15.0 \pm 5.0$ & $-15.6 \pm 7.8$ & $1.4 \pm 6.1$ & $-1.7 \pm 6.0$ & $-1.8 \pm 8.7$ & $-6.5 \pm 7.5$ \\
\hline Angle at Toe-off / Ball impact $\left(^{\circ}\right)$ & $-6.7 \pm 4.5$ & $-24.2 \pm 5.8$ & $5.1 \pm 6.3$ & $11.9 \pm 2.3$ & $1.3 \pm 8.9$ & $0.9 \pm 6.7$ \\
\hline Range of Motion $\left(^{\circ}\right)$ & $8.2 \pm 5.9$ & $7.9 \pm 5.3$ & $5.5 \pm 2.5$ & $13.6 \pm 4.4$ & $4.0 \pm 2.7$ & $8.4 \pm 3.6$ \\
\hline Peak Range of Motion $\left(^{\circ}\right)$ & $10.8 \pm 3.8$ & $1.8 \pm 1.5$ & $4.4 \pm 3.1$ & $17.1 \pm 4.8$ & $2.5 \pm 2.9$ & $17.4 \pm 7.1$ \\
\hline Peak Angle $\left(^{\circ}\right)$ & $-4.1 \pm 4.3$ & $-14.5 \pm 7.8$ & $-3.0 \pm 6.5$ & $15.8 \pm 3.8$ & $-4.3 \pm 8.7$ & $10.8 \pm 3.7$ \\
\hline
\end{tabular}



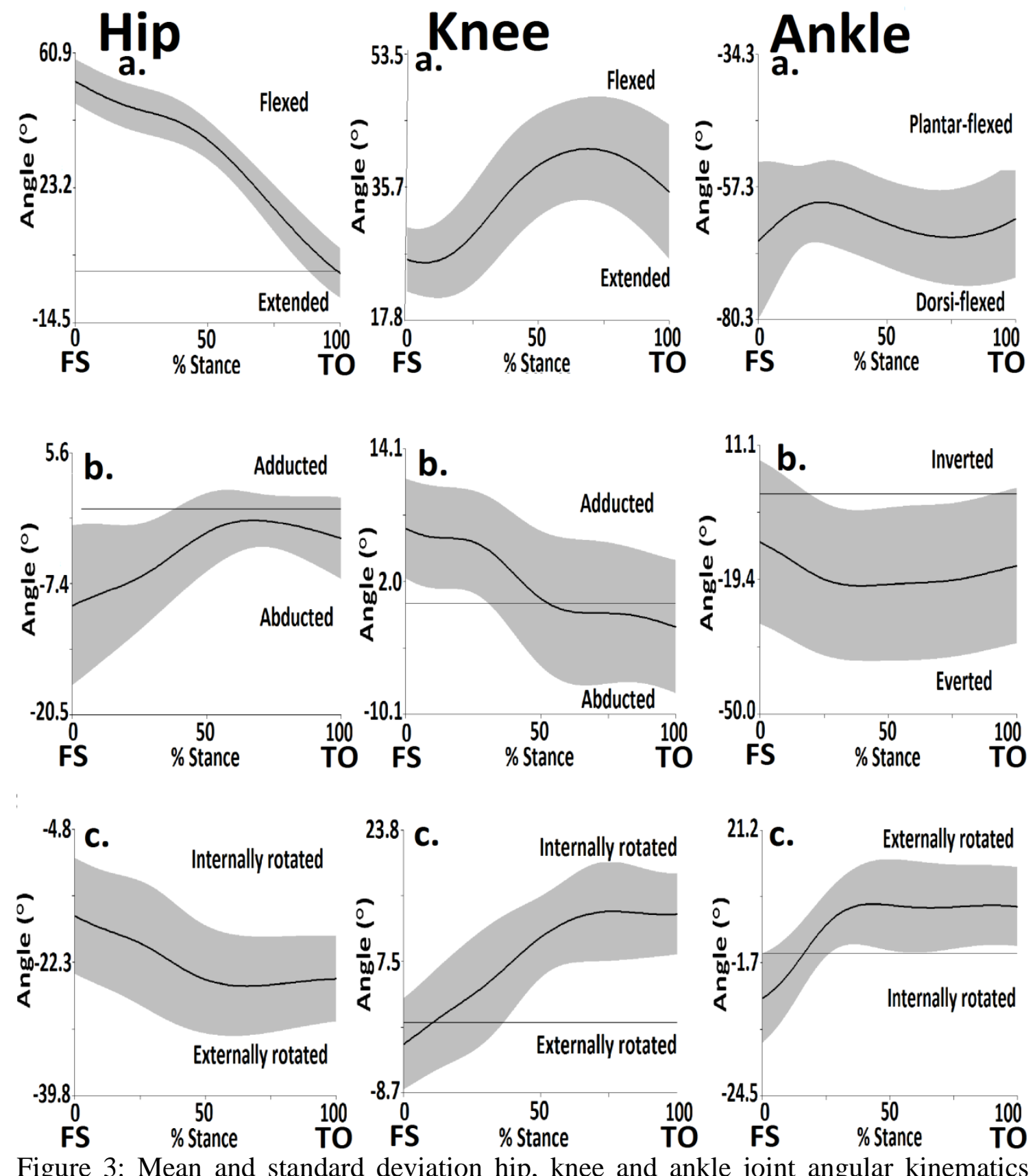

TO FS

$\%$ Stance

TO from the stance limb in the a. sagittal, b. coronal and c. transverse planes (shaded area is $1 \pm \mathrm{SD})(\mathrm{FS}=$ stance limb footstrike, $\mathrm{TO}=$ stance limb take-off $)$. 

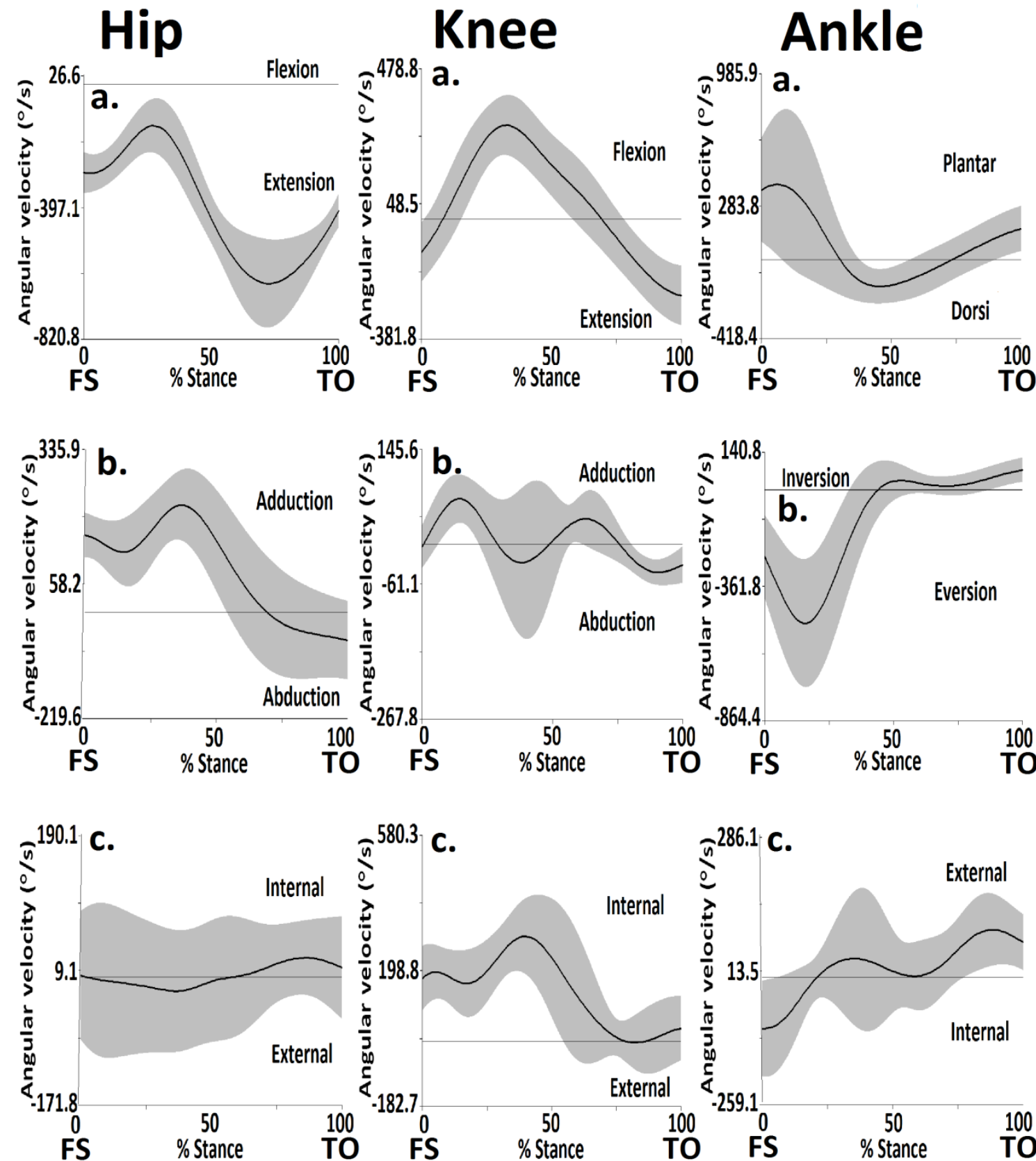

Figure 4: Mean and standard deviation hip, knee and ankle joint angular velocities from the stance limb in the a. sagittal, b. coronal and c. transverse planes (shaded area is 1 $\pm \mathrm{SD})(\mathrm{FS}=$ stance limb footstrike, $\mathrm{TO}=$ stance limb take-off). 
220 Table 2: Hip, knee and ankle joint velocities (means and standard deviations) from both the stance and kicking limbs.

\begin{tabular}{|c|c|c|c|c|c|c|}
\hline & \multicolumn{2}{|c|}{ Hip } & \multicolumn{2}{|c|}{ Knee } & \multicolumn{2}{|c|}{ Ankle } \\
\hline $\begin{array}{c}\text { Sagittal Plane }(+=\text { flexion } / \text { - } \\
=\text { extension })\end{array}$ & Kick & Stance & Kick & Stance & Kick & Stance \\
\hline Velocity at Footstrike $\left({ }^{\circ} \cdot \mathrm{s}^{-1}\right)$ & $45.4 \pm 59.4$ & $-288.1 \pm 61.6$ & $780.6 \pm 171.4$ & $-102.3 \pm 41.8$ & $288.6 \pm 78.1$ & $320.4 \pm 201.5$ \\
\hline $\begin{array}{c}\text { Velocity at Toe-Off / Ball impact }\left({ }^{\circ} \cdot \mathrm{s}^{-}\right. \\
\left.{ }_{1}\right)\end{array}$ & $-24.8 \pm 63.1$ & $-367.3 \pm 130.4$ & $-1554.8 \pm 254.4$ & $-184.4 \pm 60.2$ & $-132.2 \pm 129.9$ & $41.4 \pm 59.1$ \\
\hline Peak Velocity $\left({ }^{\circ} . \mathrm{s}^{-1}\right)$ & $450.2 \pm 62.3$ & $-724.6 \pm 120.2$ & $893.5 \pm 100.2$ & $262.4 \pm 39.4$ & $292.9 \pm 66.3$ & $-127.9 \pm 69.6$ \\
\hline \multicolumn{7}{|l|}{$\begin{array}{c}\text { Coronal plane }(+=\text { adduction/ - } \\
=\text { abduction })\end{array}$} \\
\hline Velocity at Footstrike $\left({ }^{\circ} \cdot \mathrm{s}^{-1}\right)$ & $-41.1 \pm 58.4$ & $156.2 \pm 38.8$ & $-135.7 \pm 79.8$ & $7.4 \pm 25.1$ & $166.0 \pm 59.3$ & $-241.3 \pm 144.6$ \\
\hline $\begin{array}{c}\text { Velocity at Toe-Off / Ball impact }\left({ }^{\circ} \cdot \mathrm{s}^{-}\right. \\
\left.{ }^{1}\right)\end{array}$ & $178.7 \pm 100.3$ & $-83.8 \pm 30.6$ & $128.6 \pm 181.7$ & $-83.8 \pm 30.6$ & $-56.8 \pm 96.3$ & $58.9 \pm 30.3$ \\
\hline Peak Velocity $\left({ }^{\circ} \cdot \mathrm{s}^{-1}\right)$ & $-153.0 \pm 47.6$ & $221.8 \pm 97.7$ & $249.4 \pm 61.3$ & $221.8 \pm 97.7$ & $208.2 \pm 81.7$ & $-501.2 \pm 200.1$ \\
\hline \multicolumn{7}{|l|}{$\begin{array}{c}\text { Transverse plane }(+=\text { internal/ - } \\
=\text { external })\end{array}$} \\
\hline Velocity at Footstrike $\left({ }^{\circ} \cdot \mathrm{s}^{-1}\right)$ & $34.2 \pm 65.7$ & $0.6 \pm 78.4$ & $132.0 \pm 120.9$ & $0.6 \pm 78.4$ & $26.9 \pm 98.2$ & $-108.7 \pm 90.5$ \\
\hline $\begin{array}{l}\text { Velocity at Toe-Off / Ball impact }\left({ }^{\circ} \cdot \mathrm{s}^{-}\right. \\
\left.{ }^{1}\right)\end{array}$ & $-77.8 \pm 81.8$ & $2.8 \pm 20.1$ & $38.9 \pm 101.2$ & $2.8 \pm 20.1$ & $111.5 \pm 121.4$ & $40.3 \pm 43.8$ \\
\hline Peak Velocity $\left({ }^{\circ} \cdot \mathrm{s}^{-1}\right)$ & $246.9 \pm 36.5$ & $-25.9 \pm 65.1$ & $-184.3 \pm 91.2$ & $-35.9 \pm 56.1$ & $-95.4 \pm 31.5$ & $101.4 \pm 53.6$ \\
\hline
\end{tabular}




\section{DISCUSSION}

222 The aim of the current investigation was to determine the 3-D kinematic parameters pertinent to the development of ball velocity during maximal punt kicking. This study represents the first to examine these factors in rugby league using elite standard kickers.

The obtained ball velocities correspond well with those obtained in rugby league/ union punt kicking analyses by Holmes et al., [15] (25.60 m.s $\left.{ }^{-1}\right)$ and Ball et al., [16] (27.80 $\left.\mathrm{m} . \mathrm{s}^{-1}\right)$. The regression analysis revealed that knee extension angular velocity of the kicking limb at ball impact and peak hip angular velocity were the best predictors of ball velocity. The fit of the multiple regression analysis $\left(\mathrm{R}^{2}=0.76\right)$ suggests that variance in ball velocity may be significantly influenced by the kicking technique employed by the player. This concurs with the early proposition by Macmillan [17] who documented that variations in ball velocity during punt kicking are influenced by alterations in kinematics.

That knee extension angular velocity at ball impact served as a strong predictor of ball velocity is unsurprising and concurs with the observations of De Witt \& Hinrichs [18] and Ball, [4] who found that knee angular velocity was significantly related to ball velocity during maximal instep soccer kicking and Australian Rules football punt kicking respectively. This observation supports the notion that the velocity of the foot which ultimately governs the resultant ball velocity is a function of the angular velocity of the shank [4]. The linear velocity of the centre of mass of the rotating foot which strikes the ball is directly proportional to the product of the angular velocity and the radius of rotation of the proximal body segments thus the strong influence of shank angular velocity on ball velocity is logical.

The second significant contributor to resultant ball velocity peak hip flexion velocity also makes empirical and practical sense. Baker \& Ball [19] observed that kickers who produced high ball speeds were associated with significantly greater maximum thigh angular velocities than in kickers who produced low ball velocities. Putnam [20] suggested that a high angular velocity of the proximal thigh segment is central in the transfer of momentum to the distal shank segment. It was hypothesized that the peak angular velocity of the thigh segment contributes to about $50 \%$ of the resultant angular velocity of the shank. The co-ordination pattern between the thigh and shank segment angular velocities throughout the kick phase is similar to those previously observed during maximal kicking in both soccer and American football [21-24]. During the latter half of the kick phase the shank angular extension velocity increased as the thigh flexion angular velocity decreased. Although the flexion angular velocity of the thigh decreased in the latter part of the movement it is still important that a high maximum thigh angular velocity be attained to facilitate greater angular velocity of the distal segments.

Based on the findings of the current investigation, recommendations for training modifications can be made in order to improve ball velocity during punt kicking. In order to improve resultant ball velocity it is recommended that coaching drills be implemented firstly with the aim of increasing sagittal plane knee angular velocity at ball contact. It has been documented that conditioning and skill drills that promote greater foot speeds and shank angular velocities, might be useful methods of training this skill [25]. There is further evidence that an efficacious strength training program 
which encompasses concentric and eccentric exercises also improves kicking distance and power [26]. Cabri et al., [27] observed high correlations between knee flexor and extensor strength and kick distance. Similarly Poulmedis [28] and Narici et al., [29] also determined that lower extremity muscle strength parameters were significantly related to ball velocity. Similarly a significant relationship between hip flexor and extensor strength was observed which was lower than that for the knee joint. This corresponds with the kinematic observations of the current investigation. As the principal contributor to knee extension and also secondarily to hip flexion, the quadriceps and psoas muscle groups would generate high intensity forces during the punt kick. Therefore, from a biomechanical perspective, the strength training for knee and hip muscle groups may be of particular importance for rugby players.

281

282

283

284

285

286

The regression analysis suggests that there is still variance in ball velocity that could not be accounted for by the 3-D kinematic parameters observed in the current investigation. It is possible that some of this will be associated with the nature of impact, reported by various authors as important for kicking tasks [24; 30-33]. Bull-Andersen et al., [34] reported that the resultant ball velocity in soccer kicking was due to foot speed and the coefficient of restitution between foot and ball. Ball flight characteristics could also alter these results, as different angles of trajectory and spin rates of the ball will alter how the ball flies through the air. Finally, whilst this study considered the contribution of the lower extremities to resultant ball velocity, no inferences were considered with regards to the arms and their influence on ball velocity. Chen \& Chang, [35] noted that arm swing significantly influences the resultant ball velocity, thus it is recommended that future analyses be conducted in order to examine in greater detail the upper body contribution to ball velocity during punt kicking.

That the current investigation utilized an all-male sample may limit its generalizability as Barfield et al., [36] documented kinematic differences in kicking kinematics during the maximal instep soccer kick. There remains currently a paucity of research regarding the mechanics of punt kicking in females, and the growth in female participation has failed to lead to a corresponding growth in the study of the mechanics of kicking in females. It is therefore recommended that the current investigation be repeated using a female sample. A further limitation of the current investigation is the small sample size. Regression analyses with multiple predictor variables can be sensitive to the number of participants. The preferred ratio of participants to number of predictor variables ranges from 5:1 - 15:1 [37], and is not adhered to in the current examination. However, smaller sample sizes are common when elite level participants are examined and it is unlikely that a sample sufficient to meet the required ratio could be recruited for a study of this nature. Furthermore, as the populations from which elite participants are drawn from are typically much smaller (than when recreational athletes are examined) it could be contended that the sample is representative of the population. The findings may therefore require further investigation in larger samples using non-elite players.

Whilst the kinetic and kinematic determinants of ball velocity/distance have been the subject of a number of investigations, the accuracy of punt kicking is also pertinent as the kick still has to reach a specific target. There is currently a paucity of research examining 3-D kinematics of movement associated with accuracy in punt kicking. Dichiera et al., [38] have performed the only investigation concerning the accuracy of 
317 drop punt kicking. They showed that accurate kickers were associated with significant

318 increases in hip flexion of both stance and kicking limbs, knee flexion in the stance limb

319 and anterior pelvic tilt; indicating that lower limb joint angles may be related to kicking 320 accuracy. However, the research conducted by Dichiera et al., [38] was comparative in nature and there remains a lack of 3-D kinematic research examining the movement patterns associated with accurate punt kicking using correlational techniques. It is recommended therefore that future investigations consider the discrete variables associated with the development of accuracy during punt kicking.

\section{CONCLUSIONS}

The current investigation shows that a significant proportion of the variance in ball velocity was explained by a small number of kinematic parameters, indicating that these parameters are clearly pertinent to the development of high ball velocities during punt kicks in rugby league. It is therefore conceivable that players may benefit from exposure to coaching and strength techniques geared towards the modification of kicking mechanics specific to this study. The outcomes from interventions utilizing biomechanical feedback to improve kicking performance are currently unknown, future work should still focus on implementing interventions to improve kicking performance.

Acknowledgements: Thanks go to Glenn Crook for his technical help and support throughout this work.

\section{References}

1. Lim, E., Lay, B., Dawson, B., Wallman, K. and Anderson, S., Development of Player Impact Ranking Matrix in Super 14 Rugby Union. International Journal of Performance Analysis of Sport, 2009, 9, 354-367.

2. de Mestre, N., The mathematics of projectiles in sport. Cambridge University Press, Cambridge, 1990.

3. Baktash, S., Hy, A., Muir, S., Walton, T. and Zhang, T., The Effects of Different Instep Foot Positions on Ball Velocity in Place Kicking. International Journal of Sports Science and Engineering, 2009, 3, 85-92.

4. Ball, K., Biomechanical Considerations of Distance Kicking in Australian Rules Football. Sports Biomechanics, 2008, 7, 10-23.

5. Ball, K., Kinematic Comparison of the Preferred and Non-Preferred Foot Punt Kick. Journal of Sports Sciences, 2011, 29, 1545-1552.

6. Dichieraa, A., Webstera, K.E., Kuilboera, L., Morrisa, M.E. Bacha, T.M., and Feller, J.A. Kinematic Patterns Associated With Accuracy of the Drop Punt Kick in Australian Football. Journal of Science and Medicine in Sport, 2006, 9, 292-298.

7. Pavely, S., Adams, R. D., Di Francesco, T., Larkham, S. and Maher, C.G. Bilateral Clearance Punt Kicking in Rugby Union: Effects of Hand Used for Ball Delivery. International Journal of Performance Analysis in Sport, 2010, 10, 187-196.

8. Orchard, J., Walt, S., McIntosh, A. and Garlick, D., Muscle Activity During the Drop Punt Kick. Journal of Sports Sciences, 1999, 17, 837-838.

9. Cappozzo, A., Catani, F., Leardini, A., Benedeti, M.G. and Della, C.U., Position and Orientation in Space of Bones During Movement: Anatomical Frame Definition and Determination. Clinical Biomechanics, 1995, 10, 171-178. 
10. Bell, A.L., Brand, R.A. and Pedersen, D.R., Prediction of Hip Joint Centre Location From External Landmarks, Human Movement Science, 1989, 8, 3-16.

11. Cappozzo, A., Cappello, A., Croce, U. and Pensalfini, F., Surface-Marker Cluster Design Criteria for 3-D Bone Movement Reconstruction. IEEE Transactions on Biomedical Engineering. 1997, 44, 1165-1174.

12. Sinclair, J., Edmundson, C.J., Brooks, D. and Hobbs, S.J., Evaluation of Kinematic Methods of Identifying Gait Events During Running. International Journal of Sports Science and Engineering, 2011, 5, 188-192.

13. Sinclair, J., Fewtrell, D., Taylor, P.J., Bottoms, L., Atkins, S. and Hobbs, S.J., Three-Dimensional Kinematic Correlates of Ball Velocity During Maximal Instep Soccer Kicking in Males, European Journal of Sports Sciences, 2014,_14, 799-805.

14. Knudson, D. and Bahamonde, R., Effect of Endpoint Conditions on Position and Velocity Near Impact in Tennis. Journal of Sports Sciences, 2001, 19, 839-844.

15. Holmes, C., Jones R., Harland A. and Petzing J., Ball Launch Characteristics for Elite Rugby Union Players, in The Engineering of Sport, Springer, 2006.

16. Ball, K., Ingleton, C., Peacock, J. and Nunome, H., Ball Impact Dynamics in the Punt Kick. In T.Y. Shiang, W.H. Ho, P.C. Huang and C.L. Tsai (Eds.), eProceedings of the $31^{\text {st }}$ Conference of the International Society of Biomechanics in Sports, B9-4 ID77. National Taiwan Normal University: Taipei, 2013.

17. Macmillan, M.B., Determinants of the Flight of the Kicked Football. The Research Quarterly, 1975, 46, 48-57.

18. De Witt, J.K. and Hinrichs, R.N., Mechanical Factors Associated with the Development of High Ball Velocity During an Instep Soccer Kick. Sports Biomechanics, 2012, 11, 382-390.

19. Baker, J., and Ball, K., Biomechanical Considerations of the Drop Punt. Technical Report for the Australian Institute of Sport AFL Football Development Squad. Canberra: Australian Institute of Sport, 1996.

20. Putnam, C.A., Segment Interaction Analysis of Proximal-to-Distal Sequential Segment Motion Patterns. Medicine and Science in Sports and Exercise, 1991, 23, 130-141.

21. Putnam, C., Sequential Motions of Body Segments in Striking and Throwing Skills: Descriptions and Explanations. Journal of Biomechanics, 1993, 26, 125135.

22. Robertson, D.G. and Mosher, R.E., Work and Power of the Leg Muscles in Soccer Kicking. In Biomechanics IX-B (edited by D.A. Winter, R.V. Norman, R.P. Wells, K.C. Hayes and A.E. Patla), pp. 533-538. Champaign, IL: Human Kinetics, 1985.

23. Putnam, C.A. and Dunn, E.G., Performance Variations in Rapid Swinging Motions: Effects on Segment Interaction and Resultant Joint Moments. In: Jonsson, B. (Eds), Biomechanics X-B. Human Kinetics Publishers, Inc., Champaign, IL, $661-665,1987$.

24. Lees, A. and Nolan, L., The Biomechanics of Soccer: A review. Journal of Sports Sciences, 1998, 16, 211-234.

25. Ball, K., Use of Weighted Balls for Improving Kicking for Distance. Journal of Sports Science and Medicine, 2007, 6, S44. 
26. DeProft, E., Cabri, J., Dufour, W. and Clarys, J.P., Strength Training and Kick Performance in Soccer Players. In Science and Football. Eds: Reilly, T., Lees, A., Davids, K., and Murphy, W.J. New York: E \& F.N. Spon, 1988, 108-113.

27. Cabri, J., De Proft, E., Dufour, W. and Clarys, J.P., The Relation Between Muscular Strength and Kicking Performance. In: Science and football. Eds: Reilly, T., Lees, A., Davids, K. and Murphy, W.J. London: E \& FN Spon, 1988, 186-193.

28. Poulmedis, P., Muscular Imbalance and Strains in Soccer. In: Sports injuries and their prevention. Eds: Van der Togt, C.R., Kemper, A.B. Proceedings 3rd meeting council of Europe. Oosterbeek; National Institute for Sports Health Care, 1988, 53-57.

29. Narici, M., Sirtori, M. and Mognoni, P., Maximal Ball Velocity and Peak Torques of Hip Flexor and Knee Extensor Muscles. In: Science and Football. Eds: Reilly, T., Lees, A., Davids, K. and Murphy, W.J. London: E \& FN Spon, 1988, 429-433.

30. Asami, T. and Nolte, V., Analysis of Powerful Ball Kicking. In H. Matsui \& K. Kobayashi (Eds.), Biomechanics VIII-B (pp. 695-700). Champaign, IL: Human Kinetics, 1983.

31. Asai, T., Nunome, H., Maeda, A., Matsubara, S. and Lake, M., Computer Simulation of Ball Kicking Using the Finite Element Skeletal Foot Model. In T. Reilly, J. Cabri, \& D. Arau' (Eds.), Science and Football V (pp. 77-82). London: Routledge, 2005.

32. Nunome, H., Lake, M., Georgakis, A. and Stergioulas, L.K., Impact Phase Kinematics of the Instep Kick in Soccer. Journal of Sports Sciences, 2006, 24, $11-22$.

33. Plagenhoef, S., The patterns of human motion. Englewood Cliffs, NJ: PrenticeHall, 1971.

34. Bull-Andersen, T., Dorge, H. C., and Thomsen, F.I., Collisions in Soccer Kicking. Sports Engineering, 1999, 2, 121-126.

35. Chen, Y., and Chang, J-H., An Investigation of Soccer Ball Velocity on Instep Kick With and Without Arm Swaying. XXVIII International Symposium of Biomechanics in Sports July 2010 Marquette, MI, USA, 2010.

36. Barfield, W.R., Kirkendall, D.T. and Yu, B., Kinematic Instep Kicking Differences Between Elite Female and Male Soccer Players. Journal of Sports Science and Medicine, 2002, 1, 72-79.

37. Stevens, J., Applied Multivariate Statistics for the Social Sciences (4th ed.). Mahwah, NJ: Lawrence Erlbaum Associates, 2002.

38. Dichiera, A., Webster, K.E., Kuilboer, L., Morris, M.E., Bach T.M. and Feller J.A., Kinematic Patterns Associated with Accuracy of the Drop Punt Kick in Australian Football. Journal of Science \& Medicine in Sport, 2006, 9, 292-298. 